Transportation Management (2018) Volume 1 doi:10.24294/tm.v1i3.460

\title{
Accessibility to Urban Services: Influence on Pedestrian Users of Public Transit
}

\section{Praveen K Maghelal*}

Sustainable Critical Infrastructure, Industrial and Systems Engineering, Khalifa University of Science and Technology, Masdar City Campus, E-mail: pmaghelal@masdar.ac.ae

\begin{abstract}
Several studies in the last two decades have investigated the role of built environment on walking. Studies that investigated the role of built environment on walking to transit analyzed the role of various destinations in proximity to the stations. However, few studies have investigated the role of these destinations on walking trip generation at the origin of the trip. Moreover, none of these studies have investigated the role of availability of public services on walking to transit. This study identifies the urban services at the origin of walking trips of the tri-rail commuters in the West Palm, Broward, and Miami-Dade Counties of South Florida. The number of pedestrian users of tri-rail stations and the available urban service were aggregated per Traffic Analysis Zones and analyzed using standard Poisson regression. Findings indicate that availability of urban services such as public education and public recreation have a positive effect on walking to commuter-rail. Implications of this study include the identification and development of Capital Improvement Projects such as libraries to be located in close proximity to schools and colleges. New and proposed train stations should be located in proximity to urban services such as school, colleges, and libraries to encourage pedestrian users.
\end{abstract}

Keywords: Urban Service; Walking; Transit; Trip Generation

\section{Introduction}

The availability of good public services is shown to have an influence on the lifestyle of individuals in a community (Kawabata \& Shen, 2007). The convenience of public transportation as a public service for work and non-work related travel has become increasingly important. Studies have shown that the availability of public transportation within walking distance can influence people to walk more and use public transit for their travel (Holtzclaw, 1994, Handy, 1996). The smart growth movement also sees transportation as a major element of land use patterns. Gregory K. Ingram (2009) suggest that "expanding transportation options, altering transportation pricing, and fostering pedestrian-friendly settings yield less single-occupant car travel, less congestion growth, and more trips by transit, biking, and walking (19). It is also interesting to note that vacancy rates are down and the cost of land near transit stations is going up. Analysis show that developers pay an average of 25 percent more for properties within a quarter-mile of an existing or planned transit stop (Wanberg, 2010). A study conducted by the University of Pennsylvania, Drexel University and the Rand Corporation concluded that individuals burn more calories when they park their cars and walk to and from transit stations. They suggest that there is a connection between light rail and positive health outcomes (MacDonald, 2010). For over half a century, city and state administrations have argued, proposed, and developed efficient public transportation services. Federal and local agencies call for the use and improvement of public transportation for inexpensive, clean, secure, and convenient travel. Currently, the use of public transportation such as light-rail, commercial/passenger trains, and bus rapid transit systems are encouraged even more due to the increase in fuel prices, and decreasing environmental health due to pollution. For instance, Florida Energy and Climate Change Action Team recommended increased use of the tri-rail, a commuter rail service in South Florida, to reduce congestion on roads, pollution from emission of vehicles, and to deal with the global demand for oil and gas 
(GATECC, 2007).

Urban service studies have reported that bundling various urban services together is an efficient and successful model for the distribution of services (Chong, 2007). These urban service plans recommend providing public services in close proximity to each other so that one efficient service can improve the use of another. Public transportation is one such service that needs immediate attention as is evident from the immense support to reduce green house gas emissions from vehicles and increase the use of public transportation. Therefore, this study investigates the impact of availability of various urban services on generating walking trips to the tri-rail commuter train in the tri-county region (Palm Beach, Broward, and Miami-Dade) of South Florida. In doing so, it seeks to answer the questions: Does the availability of certain types of urban services have an impact on generating walking trips to the tri-rail stations compared to other services? Or does the bundling of all services impact tri-rail use?

The paper discusses the existing literature in the urban service distribution model. This framework sets the context for the work by grounding the present study in the research. At this point, the methodology and analysis used to investigate the proposed research questions are described. Next the paper identifies the urban services at the origin of walking trips of the tri-rail commuters in the West Palm, Broward, and Miami-Dade Counties of South Florida. The number of pedestrian users of tri-rail stations and the available urban services are aggregated per Traffic Analysis Zones and analyzed using standard Poisson regression. Later sections discuss the results of these analyses, their implications and future research opportunities.

\subsection{Urban Service Delivery}

William Baer (1985) defined urban service as "one which serves the public interest by accomplishing one or more of the following purposes: preserving life, liberty and property; and promoting public enlightenment, happiness, domestic tranquility and the general welfare. It is provided by one or more of the sectors in the economy through government regulation, co-production, or direct provision" (page.886) Lee (1994) classified urban services into (1) Administrative services such as water, sewer, parks, police, and fire; (2) mixed services such as education and welfare (3) mixed services such as libraries and cultural activities; and (4) political services such as health, housing and development.

Allocation of these urban services and their socio-spatial grouping within geographic boundaries such as cities and municipalities have been the crux of spatial investigations (Kawabata and Shen, 2007; Chong, 2007; Cho and Choi, 2005). These spatial analyses have posited that combining services together improve the efficiency of urban service delivery. For instance, Wolch (1981) investigated the role of bundling services on service-dependent housing. Her analysis suggested that urban service facilities should be located in close proximity to service-dependent areas in order to improve the efficiency of the services. Improved access to services thus, can be achieved when sufficient and important facilities are geographically located in close proximity to each other. This being the case, accessibility of urban services such as schools and libraries may improve the accessibility to public transportation.

\subsection{Urban Services and Public Transit}

Spatial distribution of urban services such as schools (Talen, 2001), parks (Cho and Choi, 2005), public health (Khaleghian, 2004), service-dependent housing (Wolch, 1981), public housing (Chong, 2007), transit use (Kawabata and Shen, 2007), and community resources (Field et al, 2004) has been discusses extensively in the last decade. Talen (2001) investigated the accessibility to schools using the distances between census blocks of student's home locations and eighty-four elementary schools. Spatial inequalities in access to schools were observed between school zones in all the three counties of West Virginia. Similarly, access to public transit services is recognized as an important task that can improve the efficiency of the urban service delivery system. However, accessibility to services is considerably low for public transit users than for car users in the United States (Hess, 2005; Kawabata, 2003; Kawabata and Shen, 2006; Shen, 1998). Therefore, it is important to investigate the proximity of services with respect to walking to public transit services because access to opportunities is increasingly recognized as an essential component of sustainable development and transport (Banister, 2002; Deakin, 2001, 2002; Richardson, 2005). 


\subsection{Urban Services and Walking to Public Transit}

The use of public transit along with other sustainable modes of transportation such as walking and biking is encouraged by transportation agencies such as the Federal Transit Administration (FTA) and health agencies such as the Center of Disease Control and Prevention (CDC). Both transportation and health professionals agree that improving accessibility to public transit is important to increase the overall activity levels of a community (Brownson \& Boehmer, 2004; Meyer \& Dumbaugh, 2004; Besser \& Dannerberg, 2005). Almost all trips by public transit involve walking to some extent. Therefore, improvement in pedestrian accessibility is highly beneficial to transit use. Accessibility by walking, in comparison to all modes of travel, is impacted the most by the availability and proximity of services. This is because the macro and micro built-environments and walking distances to available services impact pedestrians the most when compared to individuals in cars, buses, or even on bike. Urban built-environments such as parks and activity centers have been shown to increase walking (Lee and Moudon, 2006; Brownson et al. 2001). Increased walking is beneficial to the use of public transit because transportation modeling studies reveal that walking communities report higher use of public transit such as light rails, commuter rail, and bus service (Cervero \& Radish 1996, Maghelal 2011).

However, distance to these services has been cited to have a significant effect on the accessibility and utilization of public transit (Kane, 1969; Dear, 1978; McLafferty, 1982; Kirby, 1982). This has been reported to be particularly true in the case of low-income communities (Kane, 1969, Campbell, Converse, \& Rogers, 1976; Kirby and Eldred 1983). As succinctly reported by Hero (1986), "Examination of a city's transportation system, both public and private, would therefore appear a necessary undertaking if the physical distance approach is to provide grounds for useful analysis, particularly where "immobile" services such as parks are the focus" (page 664).

Although the use of public transit system has been analyzed for improved ridership through accessibility from the origin of travel (Cervero \& Gorham, 1995; Besser \& Dannerberg, 2005), the impact of accessibility of other urban services remains to be explored. This study therefore investigates the impact of the availability of different types of urban services on generating pedestrian users to the tri-rail stations in the tri-county region of South Florida. Responses obtained from the 2007 on-board survey were used identify the Traffic Analysis Zones (TAZs) of the respondents and their accessibility (availability in count) to the urban services in each TAZ. This survey was conducted by the tri-rail service in association with the South Florida Regional Transportation Authority (SFRTA) in fall of 2007. This study therefore uses TAZs as units of analysis, similar to the study conducted by Kawabata and Shen (2007) that used regional TAZs as the unit of analysis.

\section{Methodology}

The present study used data from the three counties in South Florida that are served by the tri-rail commuter rail service: Palm Beach, Broward, and Miami-Dade. Palm Beach County is located to the north of Broward and Miami-Dade Counties and is served by the tri-rail commuter service. The three counties house the City of West-Palm, City of Fort Lauderdale, and City of Miami respectively. The Tri-Rail is a local commuter railway that travels North and South through the three counties, Miami-Dade, Broward, and Palm Beach Counties. The railway travels approximately 72 miles, start to finish, and incorporates 18 stations. Recent years have seen a small surge in average daily ridership as shown in Figure 1. 
Average Daily Ridership by Station, 2002-2006

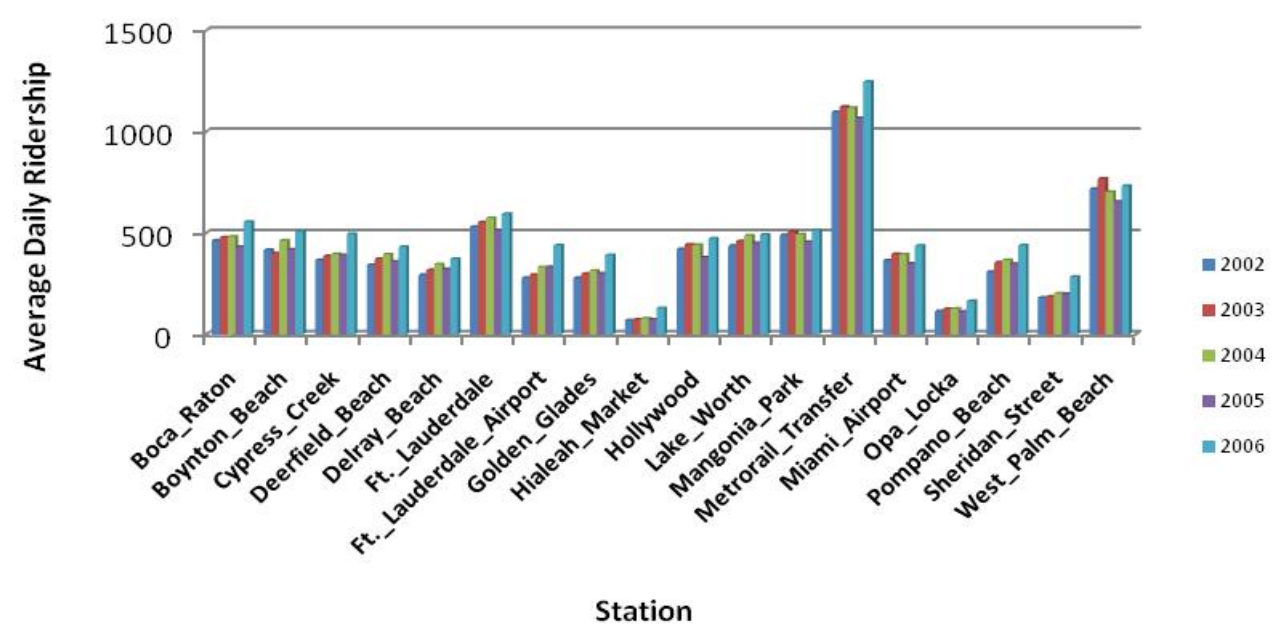

Figure 1; Average daily ridership per each tri-rail station for 2002-2006.

\subsection{Dependent Variable}

This study used the responses of the Tri-rail onboard survey conducted in 2007 along the tri-rail corridor. The onboard survey inquired about the location of origin of travel and mode of transportation to the station, along with other questions regarding satisfaction of the service. For this study, the origin of the respondents was geo-coded and aggregated for every Traffic Analysis Zone (TAZ) in the tri-county area. Only those TAZs with at least one respondent were selected and used for further analysis. Therefore, with the TAZ as the unit of analysis, the number of transit users who walk to the transit station was used as the dependent variable. In total, 175 TAZs were identified for this study.

\subsection{Independent Variables}

This study uses the framework defined by Lee (1994) to identify the type of urban services as indicators of pedestrian users to the tri-rail stations. Locational analysis was performed to identify the number of available urban services in each TAZ. For instance, the number of police stations (law enforcement stations) and fire stations within each TAZ were collectively identified as total public safety service within each TAZ. A similar procedure was followed to evaluate the public utilities, public transportation, public education, public recreation, public health, and location of public housing units in each study Traffic Analysis Zone.

Demographic variables such as the population density, employment density, residential density, median income, and vehicles per household are included in the analysis. Additionally, distance to the transit station is included because studies dating back even a decade ago, report distance as an important barrier to walking to transit station (Loutzenheiser, 1997). Therefore, we analyze this phenomenon by using a straight line distance between the centroid of each study TAZ and the station, as measured in GIS and include it in the analysis as a control variable in the study. Also, station characteristics may attract individuals to walk to a particular station in comparison to others. Therefore, individual users were queried regarding the station's cleanliness, facilities, security, parking and other help and were ranked on a Likert scale from 'Very Good' (5) to 'Very Poor' (1). The average value of each users ranking and the averages for each study TAZ were used for further analysis. Average individual responses to the characteristics of the station were included as control variables in the analysis. 


\begin{tabular}{|c|c|c|c|}
\hline Independent Variables & $\begin{array}{l}\text { Expected } \\
\text { Relation }\end{array}$ & Measure (per TAZ) & Data Source \\
\hline \multicolumn{4}{|l|}{ BASE VARIABLES } \\
\hline Population Density & + & Population per unit & US Census \\
\hline Employment Density & + & employment per unit & US Census \\
\hline Residential Density & + & Housing Units per unit & US Census \\
\hline Median Income & - & Median Income & US Census \\
\hline Vehicles per $\mathrm{HH}$ & - & Vehicles per $\mathrm{HH}$ & US Census \\
\hline Distance to Station & - & Distance $(\mathrm{mi})$ from Station & GIS \\
\hline Station Facilities & + & $\begin{array}{l}\text { Likert scale of cleanliness, safety, } \\
\text { security, and facilities at station }\end{array}$ & Survey \\
\hline \multicolumn{4}{|l|}{ ADMINISTRATIVE SERVICES } \\
\hline Public Safety & + & & \\
\hline Police Stations & & No. of law enforcement stations & FDGL \\
\hline Fire Stations & & No. of fire stations & FDGL \\
\hline Public Utilities & - & & \\
\hline Water Treatment Plant & & No. of water treatment plants & FDGL \\
\hline Sewage Treatment Plant & & No. of sewage treatment plants & FDGL \\
\hline Solid waste Treatment Plant & & No. of solid waste treatment plants & FDGL \\
\hline Public Transportation & + & & \\
\hline Bus Routes & & No. of bus routes & FDGL \\
\hline Bus Stops & & No. of bus stops & FDGL \\
\hline \multicolumn{4}{|l|}{ MIXED SERVICES } \\
\hline Public Education & + & & \\
\hline Schools & & No. of public schools & FDGL \\
\hline Colleges & & $\begin{array}{l}\text { No. of Community colleges and } \\
\text { universities }\end{array}$ & FDGL \\
\hline Public Recreation & + & & \\
\hline Library & & No. of public libraries & FDGL \\
\hline Museum & & No. of Museums and Galleries & FDGL \\
\hline \multicolumn{4}{|l|}{ HUMAN SERVICES } \\
\hline Public Health & + & & \\
\hline Hospitals & & No. of hospitals & FDGL \\
\hline Short-term Care Centers & & No. of clinics, health centers & FDGL \\
\hline Long-term Care Centers & & No. of asst. living \& residential treatment & FDGL \\
\hline
\end{tabular}

FDGL-Florida Data \& Geographic Lab

Table 1. Measures, expected relation, and data sources of independent variables 


\subsection{Administrative Services}

Three types of the administrative services were used to predict walking behavior to public transportation services: public safety, public utilities, and public transportation (Table 1). Public safety is measured as the total number of law enforcement and fire stations in each TAZ. Availability of these services in each TAZ is expected to correlate with higher counts of walking to tri-rail stations. Public utilities such as water treatment plants, sewage treatment plants, and solid waste treatment plants in each TAZ are expected to reduce the attractiveness of walking in communities and therefore, it is expected that it would be correlated with lower counts of walking to tri-rail stations. Availability of complementary public transportation such as Bus and Rapid Transit supports the use of mass transit systems such as the commuter rail service. All things held equal, public transportation service can be expected to be positively related to the use of tri-rail service for work and non-work related travel.

\subsection{Mixed Services}

The proximity to mixed services such as public education and public recreation is expected to be positively related to the use of tri-rail ridership (Table 1). Public education is measured as the number of public schools (not including private and charter schools), community colleges, and universities supported by state and local funding. Proximity of tri-rail stations to schools and colleges is expected to correlate with higher use of tri-rail services by those who walk. Likewise, institutional services such as a public library and museums attract a large number of local and non-local users. Therefore, all things held equal, the presence of institutional services can be expected to increase the use of the urban public transportation service of tri-rail.

\subsection{Human Services}

Traditionally, local governments have been responsible for law enforcement, fire protection, emergency services, education, public works, and some public health services. They have also provided services and facilities that appeal to limited segments of the community for example, libraries, museums, civic centers, transportation, and recreational facilities. More recently, they have become responsible for services that were once traditionally found in the federal government. These include human service programs designed to help the poor and disadvantaged. The location of these services is key to participation in public transportation and increase walking. Increased health services such as hospitals, short-term care centers such as clinics and intermediate care facilities, and long-term care facilities such as assisted living facilities, hospice, and homemaker and companion services are expected to increase tri-rail use and walking in general (Table 1).

\subsection{Statistical Procedures}

The distribution of the count of tri-rail users in the study TAZs is significantly skewed, with over half of the TAZs reporting only one tri-rail user who walks to tri-rail stations (98 of 175). Therefore, a standard Poisson regression which accounts for this conditional variance of the distribution of tri-rail users from each TAZ was used for the analysis. With the distance to a tri-rail station from each TAZ as the control variable, Poisson regression was performed to identify the service that is statistically significant and most impacts walking to a tri-rail station from the study Traffic Analysis Zone.

\section{Results}

In all, 175 TAZs were selected based on the location of tri-rail users who walk to the station. Over $55 \%$ of these TAZs reported only a single user who walked to a tri-rail station (97 of 175). The maximum distance of walking from the study TAZs to the station was reported as 2.24 miles with a mean distance of 0.37 miles for all the TAZs to their respective stations. This was calculated using the straight distance between the respondent's origin and the station to which they walked, as reported in the survey. Residential density and the public health services were appropriately transformed to represent the normal distribution for the regression analysis.

Next, the regression analysis was modeled for the count distribution of tri-rail users. As previously stated, since a large number of TAZs reported only one user who walked to a tri-rail station, the data was analyzed using Poisson regression to account for skewed data. Independent variables were loaded incrementally starting with the baseline variables and ending with the complete model consisting of all the urban services measured for this study. Table 2 
shows the statistics for the incremental models and displays the regression coefficients as percent changes in the expected count of tri-rail users who walk to stations for a unit change and standard deviation changes in the independent predictors.

\begin{tabular}{|l|l|l|l|l|}
\hline Variables & Model 1 & Model 2 & Model 3 & Model 4 \\
\hline BASE VARIABLES & & & & \\
\hline Population Density & $0.0001278^{\mathrm{c}}$ & $0.0001010^{\mathrm{c}}$ & $0.0000987^{\mathrm{c}}$ & $0.0001003^{\mathrm{c}}$ \\
\hline Employment Density & 0.0000924 & $-0.0001128^{\mathrm{a}}$ & $-0.0001708^{\mathrm{c}}$ & $-0.0001772^{\mathrm{c}}$ \\
\hline Residential Density & $-0.0405252^{\mathrm{c}}$ & $-0.0365731^{\mathrm{c}}$ & $-0.0378904^{\mathrm{c}}$ & $-0.0388227^{\mathrm{c}}$ \\
\hline Median Income & -0.0000016 & -0.0000031 & -0.0000050 & -0.0000054 \\
\hline Vehicles per HH & $-1.3995180^{\mathrm{c}}$ & $-1.3534280^{\mathrm{c}}$ & $-1.4951750^{\mathrm{c}}$ & $-1.5234260^{\mathrm{c}}$ \\
\hline
\end{tabular}

\begin{tabular}{|l|l|l|l|l|}
\hline ADMINISTRATIVE SERVICES & & & \\
\hline Public Safety & - & $0.3554617^{\mathrm{c}}$ & 0.0144301 & 0.0207081 \\
\hline Public Utilities & - & $-0.0978866^{\mathrm{a}}$ & $-0.1000493^{\mathrm{b}}$ & $-0.0982440^{\mathrm{b}}$ \\
\hline Public Transportation & - & -0.0038390 & $-0.0089868^{\mathrm{a}}$ & $-0.0095194^{\mathrm{a}}$ \\
\hline
\end{tabular}

\begin{tabular}{|l|l|l|l|l|}
\hline MIXED SERVICES & & & & \\
\hline Public Education & - & - & $0.2342331^{\mathrm{c}}$ & $0.2284913^{\mathrm{c}}$ \\
\hline Public Recreation & - & - & $0.1394350^{\mathrm{c}}$ & $0.1450473^{\mathrm{c}}$ \\
\hline
\end{tabular}

\begin{tabular}{|l|l|l|l|l|}
\hline HUMAN SERVICES & & & & \\
\hline Public Health & - & - & - & 0.0696439 \\
\hline
\end{tabular}

\begin{tabular}{|l|l|l|l|l|}
\hline Constant & 4.6675100 & 4.7113040 & 4.8635940 & 4.8538470 \\
\hline LR chi2(12) & 412.9600000 & 437.8600000 & 500.6000000 & 502.8200000 \\
\hline Prob $>$ chi2 & $<0.001$ & $<0.001$ & $<0.001$ & $<0.001$ \\
\hline Pseudo R2 & 0.2214000 & 0.2354000 & 0.2691000 & 0.2703000 \\
\hline Log likelihood & -726.1242800 & -711.0465000 & -679.6783000 & -678.5683300 \\
\hline
\end{tabular}

$$
{ }^{\mathrm{a}} \mathrm{p}<0.05 ;{ }^{\mathrm{b}} \mathrm{p} \leq 0.01 ;{ }^{\mathrm{c}} \mathrm{p} \leq 0.001
$$

Table 2. Poisson Regression Models Predicting the Number of Individuals Walking to Tri-rail Stations

The baseline model $(\mathrm{p}<0.001)$ with demographic variables and the control variable explained 22 percent variance in walking to tri-rail while controlling for distance and station characteristics. As expected, the population $(b=0.00013$, $\mathrm{p}<0.001)$ and residential density $(\mathrm{b}=-0.0405, \mathrm{p}<0.001)$ reported significant effects on number of users walking to tri-rail stations. Vehicles per household reported a significant negative relation with number of users walking to tri-rail $(b=-1.399, p<0.001)$. As reported in Table 3, for a given unit change in residential density, the expected count of individual users walking to tri-rail stations decreases by about 4 users. This result is contrary to those reported by other studies and may need further investigation (Forsyth et al., 2007; Rodriguez et al 2009). It should also be noted that an increase in vehicles per household by single unit reduces the expected count of number of users walking to tri-rail stations by 75 users. The regression model that included administrative services improved the overall explanatory power of the model (R-square) to $23.5 \%$. While proximity to public safety services such as law enforcement locations and fire stations $(b=0.356, p<0.001)$ was positively related to walking to tri-rail stations, proximity to treatment plants was negatively related to walking $(b=0.098, p<0.05)$. Increase in one count of police and fire stations significantly increases 
the expected count of number of users walking to tri-rail stations by about 43 users, while increase in one unit of a utility service decreases the expected count of number of users walking to tri-rail stations by around 9 individuals. In terms of population density, a change in one standard deviation increases the expected count of the number of users walking to tri-rail stations by 30 individuals. However, a change in the standard deviation of employment and residential density decreases the expected count of the number of users walking to tri-rail stations significantly (13.8 and 34.1, respectively).

\begin{tabular}{|c|c|c|c|c|c|c|c|c|}
\hline \multirow[b]{2}{*}{ Variables } & \multicolumn{2}{|c|}{ Model 1} & \multicolumn{2}{|l|}{ Model 2} & \multicolumn{2}{|l|}{ Model 3} & \multicolumn{2}{|l|}{ Model 4} \\
\hline & Unit $\Delta$ & $\mathrm{SD} \Delta$ & Unit $\Delta$ & $\mathbf{S D} \Delta$ & Unit $\Delta$ & $\mathbf{S D} \Delta$ & Unit $\Delta$ & SD $\Delta$ \\
\hline \multicolumn{9}{|l|}{ BASE VARIABLES } \\
\hline Population Density & 0.0 & 39.0 & 0.0 & 29.9 & 0.0 & 29.1 & 0.0 & 29.6 \\
\hline Employment Density & 0.0 & -11.4 & 0.0 & -13.8 & 0.0 & -20.2 & 0.0 & -20.8 \\
\hline Residential Density & -4.0 & -36.9 & -3.6 & -34.1 & -3.7 & -35.1 & -3.8 & -35.8 \\
\hline Median Income & 0.0 & -2.8 & 0.0 & -5.4 & 0.0 & -8.6 & 0.0 & -9.3 \\
\hline Vehicles per HH & -75.3 & -32.9 & -74.2 & -32.0 & -77.6 & -34.7 & -78.2 & -35.2 \\
\hline \multicolumn{9}{|c|}{ ADMINISTRATIVE SERVICES } \\
\hline Public Safety & & & 42.7 & 19.6 & 1.5 & 0.7 & 2.1 & 1.0 \\
\hline Public Utilities & & & -9.3 & -13.9 & -9.5 & -14.2 & -9.4 & -14.0 \\
\hline Public Transportation & & & -0.4 & -5.2 & -0.9 & -11.8 & -0.9 & -12.5 \\
\hline \multicolumn{9}{|l|}{ MIXED SERVICES } \\
\hline Public Education & & & & & 26.4 & 17.6 & 25.7 & 17.1 \\
\hline Public Recreation & & & & & 15.0 & 23.0 & 15.6 & 24.0 \\
\hline \multicolumn{9}{|l|}{ POLITICAL SERVICES } \\
\hline Public Health & & & & & & & 7.2 & 6.3 \\
\hline \multicolumn{9}{|l|}{ CONTROL VARIABLES } \\
\hline Distance to Station & -47.8 & -17.3 & -48.0 & -17.4 & -11.2 & -3.4 & -7.4 & -2.2 \\
\hline Station Facilities & -12.2 & -14.3 & -14.8 & -17.3 & -14.7 & -17.2 & -14.5 & -17.0 \\
\hline LR & \multicolumn{2}{|l|}{412.955} & \multicolumn{2}{|l|}{437.862} & \multicolumn{2}{|l|}{500.598} & \multicolumn{2}{|l|}{502.818} \\
\hline Prob $>$ LR & \multicolumn{2}{|l|}{0.000} & \multicolumn{2}{|l|}{0.000} & \multicolumn{2}{|l|}{0.000} & \multicolumn{2}{|l|}{0.000} \\
\hline McFadden's R2 & \multicolumn{2}{|l|}{0.221} & \multicolumn{2}{|l|}{0.235} & \multicolumn{2}{|l|}{0.269} & \multicolumn{2}{|l|}{0.270} \\
\hline McFadden's Adj R2 & \multicolumn{2}{|l|}{0.213} & \multicolumn{2}{|l|}{0.224} & \multicolumn{2}{|l|}{0.255} & \multicolumn{2}{|l|}{0.255} \\
\hline Cragg-Uhler R2 & \multicolumn{2}{|l|}{0.906} & \multicolumn{2}{|l|}{0.919} & \multicolumn{2}{|l|}{0.944} & \multicolumn{2}{|l|}{0.944} \\
\hline Log-Likelihood (Full Model) & \multicolumn{2}{|c|}{-726.124} & \multicolumn{2}{|c|}{-711.046} & -679.678 & & -678.568 & \\
\hline
\end{tabular}

Table 3. Poisson Regression Coefficients Expressed as Percent Change in Expected Count for Tri-rail Users Walking to Station for Every Unit and Standard Deviation Increase in Predictors

The next set of variables showed significant results. The mixed services group which was composed of public education and public recreation were incorporated in model 3 which reported to be statistically significant at $\mathrm{p}<0.001$. Availability of public utilities $(b=-0.1, p<0.01)$ and bus service $(b=-0.009, p<0.05)$ reported a significant negative relation with walking to tri-rail stations. The role of public transportation reported results contrary to expectation. On the other hand, public education institutions such as public schools and colleges $(b=0.234)$ and public recreation such as libraries and museums $(b=0.139)$ reported a significant positive relation with walking to tri-rail $(p<0.001)$. It should 
also be noted that inclusion of mixed services improved the overall explanatory power of the model to about 27 percent. One unit change in availability of schools and colleges increases the expected count of number of users walking to tri-rail stations by 26 individuals, while proximity to another library or museum increases the expected count of number of users walking to tri-rail stations by 15 individuals. The saturated model with all the three types of urban services explained a little over 27 percent of variance in walking to tri-rail. Interestingly, human services measured by proximity to hospitals, short-term, long-term care facilities did not report any significant relation to walking to tri-rail stations, nor did it significantly improve the explanatory power of the model.

In summary, density variables along with vehicles per household $(b=-1.523)$, public utilities $(b=-0.098)$, public transportation $(b=-0.01)$, public education $(b=0.229)$, and public recreation $(b=0.145)$ were all statistically significant predictors of walking to tri-rail stations in the final (expanded) model $(\mathrm{p}<0.001)$. Of all the variables included in the final model, a change in one unit of vehicles per household decreased the expected count by 78.2. In public education it increased the expected count by 25.7. And finally, in public recreation it increased the expected count by 15.6. These final three variables proved to have the maximum impact on the number of tri-rail users.

\section{Discussion}

Including urban services as predictors explains the variation in walking to a tri-rail stations better than demographic variables alone. However, not all urban services improve or positively impact walking to tri-rail stations. For instance, public utilities and public transportation reported negative effect on walking to tri-rail. This relation indicates that the proximity to utilities such as water treatment and sewage treatment does not attract or encourage walking in general and thus does not have a positive influence on walking to use commuter rail for work and non-work related travel. Also, availability of public transportation services, such as bus rapid transit will encourage individuals to travel to rail station by bus rather than by walking. Therefore, rail stations with connecting bus service can be expected to report low walking to rail stations.

On the contrary, prospective rail users such as individuals in school and college are more inclined to use commuter rail service for their travel. Hence, the positive significant relation indicates that the proximity of schools and colleges to rail stations increases the possibility of commuters walking to rail stations. Also, recreation activities supported by public funds such as public libraries and museums can be attractive destinations for individuals of the community. Communities with attractive destinations have reported an increase in the overall activity of the community through walking, biking, and other modes of travel (King et al., 2003). Thus, the presence of such recreation activities can significantly increase the number of individuals walking to rail stations.

Results of this study show that some urban services, such as utilities services, negatively impact walking to use public transit. This may owe to fact that the individuals of communities perceive some services less safe or attractive than others. This indicates that perceptions of individuals who are prospective users of public transportation play an important role in choosing to walk or use public transit services. Therefore, an individual's perception of what urban services encourage or discourage their use of a certain service needs to be included in future studies. According to MacDonald (2010) "Given that perceptions of neighborhood environments are independently associated with improved health outcomes, and that individuals who choose to use Light Rail Transit obtain some relative weight reduction, it would be prudent to encourage public policies that improve the safety and attractiveness of pedestrian environments that link home, work and transit stops to increase use of public transit for commuting to work. Public policy investments in transit should consider potential increases in physical activity as part of the broader set of cost-benefit calculations of transit systems. Land- use planning and travel choice have a clear impact on health outcomes. Public transit systems can generate positive health impacts by encouraging greater numbers of users to walk to station stops and maintain more physically active lives" (Page 111).

\section{Conclusions and Implication}

This study shows that the availability of certain services, although not all, does improve the walkability of 
communities and the use of public transportation for an individual's travel. Inferential analysis provides useful information regarding the bundling of services to improve the collective use of urban transit services. However, the assumption that greater quantities of services or facilities mean improved or enhanced service may not be true. The quality of the services measured through the type of specific service, the number of beneficiaries, client satisfaction, and the size of the facility along with accessibility (as measured in this study) is more likely to dictate the success of an urban service facility. Follow up studies should include the measure of the quality of these urban services and their impact on the use of public transit service. Additionally, aspects of accessibility such as distance of each service from the transit users, inclusion of all administrative, mixed, and human service facilities and the cost of operation of these services can improve the predictability of walking to use public transportation services.

Proximity (measured by distance) has been shown as an important factor that influences the decision of whether to walk to and from work or non-work related travel (Cervero 1996; Kockelman 1997). Availability of attractive destinations in close quarters can encourage people to be more active and possibly increase walking and biking in the community. It is therefore imperative that in this era of increased fuel costs, congested roads, and extensive pollution, that the use of mass transit be encouraged. Juxtaposing attractive and or practical destinations close to mass transit can encourage people to walk, thus meeting their everyday activity levels of 30 minutes or more (CDC, 2001; Saelens et al, 2003) and travel using mass transit systems. Careful planning to locate urban services in places that can positively influence the use of public transportation is important. Availability of public transit that is conveniently located close to places of employment, schools, and colleges can encourage individuals to use public transit instead of their private cars, thus reducing the ill-effects of extensive auto travel.

Finally, the results of the present study provide strong evidence that bundling of certain urban services can improve and increase the use of commuter rail systems by encouraging individuals to walk to mass transit stations. This is even more important because health professionals and environmental planners along with transportation planners encourage walking on an everyday basis and using public transportation to avoid further detrimental effects on the natural environment.

\section{References}

1. Baer WC. Just what is an urban service, anyway. The Journal of Politics 1985; 47(3): 818-898.

2. Banister D. Transport Planning 2002; 2nd edition London: Spon Press.

3. Besser LM, Dannerberg AL. Walking to public transit. steps to help meet physical activity recommendations. American Journal of Preventive Medicine 2005; 29(4):273-280.

4. Brownson RC, Baker EA, Housemann RA et al. Brennan LK et al. Bacak SJ et al. Environmental and policy determinants of physical activity in the united states. American Journal of Preventive Medicine 2001; 91: 995-2003.

5. Brownson RC, Boehmer TK. Patterns and trends in physical activity, occupation, transportation, land use, and sedentary behaviors 2004; Department of community health and prevention research center, school of public health, St. Louis university. Prepared for the committee on physical activity, health, transportation, and land use, June 25.

6. Campbell A, Converse PE, Rogers WL, et al. The quality of American life: Perceptions, evaluations and satisfactions 1976; New York: Russell Sage Foundation.

7. Center for Disease Control and Prevention (CDC), Increasing Physical Activity. Morbidity and Mortality Weekly Report 2001; US Department of Health and Human Services.

8. Cervero R, Gorham R. Commuting in transit versus automobile neighborhoods. Journal of American Planning Association 1995; 61: 210-225.

9. Cervero R. Mixed land-uses and commuting: Evidence from the American Housing Survey, Transportation Research A 1996; 30: 361-77.

10. Cervero R, Radisch C. Travel choices in pedestrian versus automobile oriented neighborhoods. Transport Policy 1996; 3(3): 127-141.

11. Cho CM, Choi YS. The effect of resident-perceived neighborhood boundary on the equity of public parks distribution: using gis, w2gis LNCS 2005; 3833: 296-307.

12. Chong, A. Bundling of basic public services and household welfare in developing countries: an empirical exploration for the case of peru, oxford development studies, 2007; 35(3): 329 - 346.

13. Deakin E. Sustainable development and sustainable transportation: strategies for economic prosperity, environmental quality, and equity 2001; Working Paper 2001-03, Institute of urban and regional development, 
university of california, berkeley, ca.

14. Deakin E. Sustainable transportation: U.S. dilemmas and European experiences, Transportation research record 2002; 1792: 1-11.

15. Dear M. Planning for mental health care: a reconsideration of public facility location theory, international regional science review 1978; 3: 93-111.

16. Field A, Witten K., Robinson E et al. Pledge $\mathrm{M}$ et al. Who gets to what? Access to community resources in two new zealand cities, urban policy and research 2004; 22(2): 189-205.

17. Forsyth A, Oakes JM, Scmitz KH et al. Hearst M et al. Does residential density increase walking and other physical activity? urban studies 2007; 44(4), 679-697.

18. Governor's Action team on energy and climate change (gatecc). 2007; Accessed at www.flclimatechange.us on June 1, 2008.

19. Handy S, Urban form and pedestrian choice: study of Austin neighborhoods, transportation research record 1996; 1552: $135-44$.

20. Hero RE. The urban service delivery literature: Some questions \&amp; Considerations, polity 1986; 18(4): 659-677.

21. Hess DB. Access to employment for adults in poverty in the buffalo-niagara region, urban studies 2005; 42: 1177-1200.

22. Holtzclaw J. Residential patterns and transit, auto dependence, and costs 1994; San Francisco: Natural Resources Defense Council.

23. Ingram Gregory K. and Yu-Hung Hong. Transportation” chapter 4 evaluating smart growth: state and local policy outcomes, policy focus report, lincoln institute of land policy report code pf020, 2009.

24. Kane R. Determinants of health care priorities and expectations among rural consumers, Health Services Research 1969; 4: 42-51.

25. Kawabata M. Job accessibility by travel mode in U.S. metropolitan areas, Theory and applications of GIS 2003;11(2): 165-172.

26. Kawabata M, Shen Q. Job accessibility as an indicator of auto-oriented urban structure: a comparison of boston and los angeles with tokyo, environment and planning b 2006; 33(1): 115-130.

27. Kawabata M, Shen Q. Commuting Inequality between cars and public transit: the case of the san francisco bay area, 1990-2000, urban studies 2007; 44(9): 1759-1780.

28. Khaleghian P. Decentralization and public services: the case of immunization, Social Science \&amp; Medicine 2004; 59: 163-183.

29. Kirby AM. The Politics of Location: An Introduction 1982; New York: Methuen Inc.

30. Kirby AM, Eldred JG. The Provision of Leisure Facilities: An Empirical and Theoretical Evaluation 1983; In Geography and the Urban Environment, ed. Herbert D and Johnston RJ, Chichester: Wiley.

31. Kockelman KM. Travel behavior as function of accessibility, land use mixing, and land use balance: Evidence from San Francisco Bay area, Transportation research record 1997; 1607: 105-115.

32. Lee C, Moudon AV. Correlated of walking for transportation or recreation purposes, journal of physical activity and health 2006;3(S1): S77-S98.

33. Lee SJ. Policy Type, Bureaucracy, and Urban Policies: Integrating models of urban service distribution, policy studies journal 1994; 22(1):87-108.

34. MacDonald, John M., Robert J. Stokes, Deborah A. Cohen, Aaron Kofner, and Greg K. Ridgeway. "The effect of light rail transit on body mass index and physical activity" American journal of preventive medicine 2010;39 (2).

35. Maghelal P. Walking to transit: influence of built environment at varying distances. institute of transportation engineers journal 2011; 81(2): 38-43.

36. McLafferty S. Urban structure and geographical access to public services, annals of the association of american geographers 1982; 72(3): 347-354.

37. Meyer MD, Dumbaugh E. Institutional and regulatory factors related to nonmotorized travel and walkable communities 2004; Prepared for the committee on physical activity, health, transportation, and land use.

38. Richardson BC. Sustainable transport: analysis frameworks, Journal of transport geography 2005; 13: 29-39.

39. Saelens BE, Sallis JF, Frank LD. Environmental correlates of walking and cycling: findings from the transportation, urban design, and planning literatures, annual behavior medicine 2003; 25(2): 80-91.

40. Shen Q. Location characteristics of innercity neighborhoods and employment accessibility of low-wage workers, environment and planning b 1998; 25(3): 345-365.

41. Talen E. School, Community, and Spatial Equity: An empirical investigation of access to elementary schools in west virginia, annals of the association of american geographers 2001; 91(3): 465-486.

42. Wandberg Tom “Apartment Seekers Willing to Pay More to be Near Light Rail” The Denver Post 2010; Article by Margaret Jackson, June 14.

43. Wolch JR. The location of service-dependent households in urban areas economic geography 1981; 57(1): 52-67. 